\title{
Static and Dynamic Mechanical Behavior of Doum Palm (Hyphaene thebaica) Nut Reinforced HDPE Composites
}

\author{
A. A. Alabi ${ }^{1, *}$, A. I. Obi ${ }^{2}$, D. M. Kulla ${ }^{3}$ and S. M. Tahir ${ }^{4}$ \\ 1,3 Department of Mechanical Engineering, Faculty of Engineering, Ahmadu Bello University PMB 1045, Zaria, Kaduna, NIGERIA \\ ${ }^{2}$ Department of Mechanical Engineering, College of Engineering and Engineering Technology, Michael Opara University of Agriculture, \\ Umudike, Abia, NIGERIA \\ ${ }^{4}$ Department of Mechanical and Manufacturing Engineering, Faculty of Engineering, Universiti Putra Malaysia, 43400 UPM Serdang, \\ Selangor, MALAYSIA
}

\begin{abstract}
The quest to discover more and to enhance the qualities of agro-residue for use as natural reinforcement of polymers continues to attract the attention of researchers because of the environmental friendliness. Hyphaene thebaica also known as doum palm is a fruit tree native to the Nile in Egypt and found in abundance in many parts of Africa. Doum palm fruit contains probably the hardest and toughest known nut. The doum palm nuts (DPN) are the most under-used hard-nut despite their abundance in nature. This study presents the potential doum palm nut particles (DPNp) as natural reinforcement for high density polyethylene (HDPE). Properties of DPN such as density, hardness and weight loss due to heating were determined. HDPE/DPNp composites were produced by reinforcing HDPE with 30, 35, 40 and 45\% DPNp particles of two different sizes. The particle sizes $600 \mu \mathrm{m}$ and $710 \mu \mathrm{m}$ led to classifying the composites as $X$-composite and $Y$-composite respectively. The static and dynamic mechanical properties of the composites were determined and compared with the those of pure HDPE. Results showed that HDPE and DPNp can be formed into light and attractive components. Loading HPDE with DPNp significantly improve static mechanical properties of HDPE such as tensile strength, hardness, stiffness and resistance to impact failure by 50\%, 200\%, 800\% and 1500\% respectively. The HDPE/DPNp composites also had better dynamic mechanical properties. The ability of the composites to maintain load bearing capacity under dynamic conditions was superior to that of HDPE.
\end{abstract}

Keywords: Static, dynamic, mechanical properties, HDPE, Hyphaene thebaica nut, doum palm nuts, composite.

\subsection{INTRODUCTION}

Hyphaene thebaica, commonly called doum palm and gingerbread tree, is a specie of palm tree that is native to the Nile in Egypt, Sudan, South Sudan and Tanzania. It also grows well in the Northern part of Nigeria, Niger Republic and Chad. The trunk and the branches of the palm usually divides into two, giving it a distinctive $\mathrm{Y}$ shape. The leaves and fibers have been used for weaving baskets. Doum palm fruit is oval shaped with dark to light brown colour. It is a single nut fruit with a very hard kernel. The outer fibrous flesh of the nut is usually chewed and spewed out or made into sweetmeats and molasses. The hard seed inside the fruit is known as vegetable ivory, it is used in making buttons, small carvings, and artificial pearls [1]. The mature Hyphaene thebaica tree produces about 50 kilograms of fruit per year. The fresh fruit is about $120 \mathrm{~g}$ each and $60 \mathrm{~g}$ when dry[1].

The quest to discover and promote the use of environmentally friendly materials with better properties

*Corresponding author (Tel: +234 (0) 806582 5887)

Email addresses: aaalabi@abu.edu.ng (A.A.

Alabi), toniobi2002@yahoo.co.uk (A.I. Obi),

dmkulla2@yahoo.com (D.M. Kulla),

su_mtahir@upm.edu.my (S.M. Tahir). for engineering and industrial application has gained interest in recent years. Prominent among these group of materials is naturally reinforced polymer composites. One advantage of natural reinforcements is the natural alignment of carbon-carbon bonds within the material structure. This inherent structure gives them robust strength and stiffness [2]. Natural reinforcements also make materials more biodegradable and lighter [2][3]. High density polyethylene (HDPE) is a thermoplastic material. It is abundant globally and relatively cheap. It is easy to process and it has some desirable properties. HDPE properties can be improved for better serviceability when natural reinforcing agent is employed [4]. Essentially, it is noteworthy to identify natural reinforcement that has received little attention in HDPE composite. Although, doum palm fiber has been extensively employed as a reinforcing agent, however, its nut has received little attention as reinforcement in HDPE composite. HDPE reinforced with doum palm nut particles (DPNp) is inexpensive with little or no negative impact on the environment.

Furthermore, DPN particles exert a better load distribution within the thermoplastic matrix compared with the natural fiber because it has better affinity. Its better affinity is not far-fetched from its inherent 
properties such as its cellulose and lignin nature which makes it more interactive with HDPE matrix. Also, there has been inconsistent report on the effect of reinforcement particle size and its loading on the properties of HDPE composite (Juhasz et al., 2004; Yao et al., 2008; Zhao et al., 2020; Hanana et al., 2020; Hubbe et al., 2020), hence, it is significant to investigate the use of DPN, its particle size and loading as reinforcing agent on the physical, mechanical and dynamic mechanical properties HDPE composite.

\subsection{MATERIALS AND METHODS \\ 2.1 Doum Palm Nut Powder Preparation.}

Matured and dried doum palm fruits were purchased from a crop market in Kaduna State, Nigeria. The fruits were slit open to remove the hard nuts. Some of the doum palm nuts (DPN) were broken into smaller sizes and ground into fine powder (described in Figure 1). Another quantity of the DPN were machined on a lathe machine into the shapes shown in Figure 2. Table 1 shows the elemental composition of DPN.

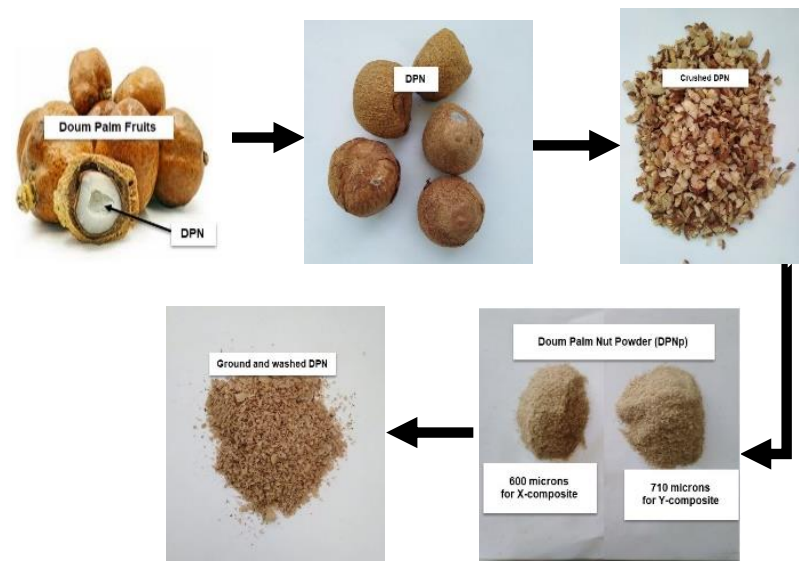

Figure 1: Processing of DPN to DPNp

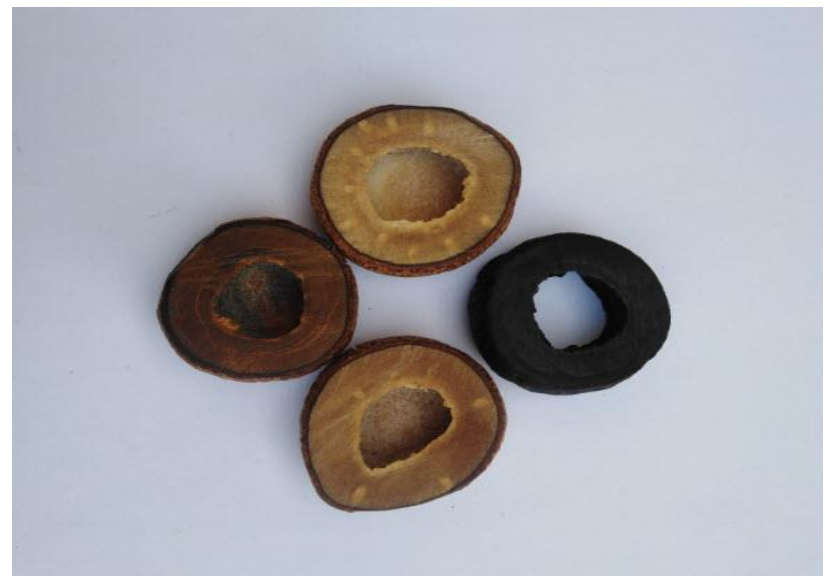

Figure 2: Geometry of Heated Samples

To remove the weak covering on the nuts, the powder was soaked in water for 12 hours at room temperature and then washed several times. The washed powder was sun-dried for 72 hours, and then sieved to obtain particle sizes of 600 and 710 microns. In this study, these particle sizes are referred to as $\mathrm{X}$ and $\mathrm{Y}$ respectively. To ensure that the moisture content of the powder $X$ and $\mathrm{Y}$ were at the same start off condition, they were kept in an oven at $30^{\circ} \mathrm{C}$ for 12 hours. This is the same treatment adopted by [5] to control the effect of fluctuation of room temperature. After which there were stored in separate desiccators. The elemental composition of the doum palm nut was determined using energy dispersion $\mathrm{x}$-ray analysis. The result is shown in Table 1

\subsection{Composite Fabrication}

Commercially available HDPE and each of the produced doum palm nut particles (DPNp) were measured in different proportions and melt-mixed in a $7200 \mathrm{VA}$ enclosure/Boiler type Two-roll mill for 30 minutes at a preheated temperature of $150^{\circ} \mathrm{C}$. The compounded mixture of HDPE/DPNp was thermoformed into a steel mold of dimension $100 \times 100 \times 5 \mathrm{~mm}^{3}$ using a $250 \mathrm{MPa}$ capacity Wenzhou Zhiguang hot press. The compression of the composite in the mold was maintained for 3 minutes and allowed to cool for 5 minutes. Composites with 30, 35,40 and $45 \%$ by weight of the DPNp fillers were produced for each of the $\mathrm{X}$ and $\mathrm{Y}$ particle sized powders. Some of the composites are shown in Figure 3. A sample with $100 \%$ HDPE was also thermoformed and used as a control. The produced HDPE/DPNp composites were cut into different standard sizes for dynamic mechanical analysis (DMA), tensile, hardness, impact tests and morphological examinations.

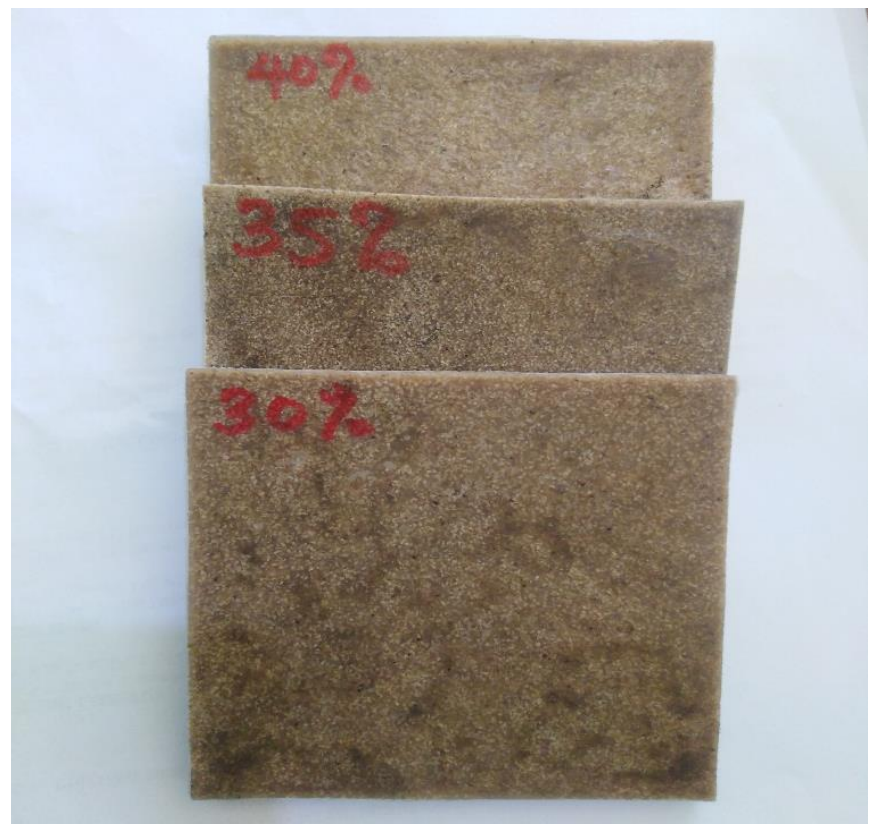

Figure 3: Samples of Formed HDPE/DPNp Composite

The density in $\mathrm{g} / \mathrm{cm}^{3}$ of the machined DPN, the thermoformed HDPE and those of the HDPE/DPNp composites were measured as a ratio of their mass to volume. 


\subsection{Preliminary Analysis on DPN}

Unlike HDPE whose properties have been extensively studied and reported in literature, DPN is a relatively an unknown nut. Some preliminary analyses were carried out to determine the hardness value, density and diametric tensile strength of DPN using samples shown in Fig. 1(a) and Fig. 1(b). The results of these tests and those of the HDPE are shown in Table 2. Dynamic mechanical properties of a material involve studying the response of the material to a range of temperature variation. Therefore, to understand the effect of heat on the produced HDPE/DPNp composites, it is imperative to understand how moisture is loss while DPN is heated. Table 3 depicts the percentage weight loss (mainly due to moisture given off) in DPN with temperature change. The geometry of the samples used for this test is shown in Figure 2. The mass of each of the samples was measured before and after heating. The percentage weight loss reported is a ratio of the mass difference to the sample mass before heating.

Table 1: Elemental Composition of Doum Palm Nut

\begin{tabular}{lccccc}
\hline Element & $\mathbf{C}$ & $\mathbf{O}$ & $\mathbf{S i}$ & $\mathbf{N b}$ & $\mathbf{K}$ \\
\hline Atomic \% & 90.84 & 4.5 & 1.98 & 2 & 0.68 \\
\hline
\end{tabular}

Table 2: Mechanical Properties and Density of DPN and HDPE

\begin{tabular}{ccccc}
\hline & Hardness Value $(\mathbf{H V})$ & $\begin{array}{c}\text { Impact Energy } \\
(\mathbf{J})\end{array}$ & $\begin{array}{c}\text { Tensile Strength } \\
(\mathbf{M P a})\end{array}$ & $\begin{array}{c}\text { Density } \\
\left(\mathbf{g} / \mathbf{c m}^{\mathbf{3}}\right)\end{array}$ \\
\hline DPN & 67.6 & & 10.21 & 1.11 \\
HDPE & 18.4 & 0.4 & 9.53 & 0.93 \\
\hline
\end{tabular}

Table 3: Effect of Heat on the Mass of Doum Palm Nuts

\begin{tabular}{cccc}
\hline $\begin{array}{c}\text { Heat Applied to DPN } \\
\left({ }^{\circ} \mathbf{C}\right)\end{array}$ & $\begin{array}{c}\text { Mass of DPN before } \\
\text { Heating }(\mathbf{g})\end{array}$ & $\begin{array}{c}\text { Mass of DPN after } \\
\text { Heating }(\mathbf{g})\end{array}$ & $\begin{array}{c}\text { Weight Loss } \\
(\boldsymbol{\%})\end{array}$ \\
\hline 30 & & & 0 \\
50 & 4.5637 & 4.5615 & 0.05 \\
100 & 4.6394 & 4.5285 & 2.39 \\
150 & 4.5686 & 4.2122 & 7.80 \\
200 & 4.3413 & 3.4991 & 19.40 \\
250 & 4.8852 & 2.5203 & 48.41 \\
\hline
\end{tabular}

\section{$2.4 \quad$ Mechanical properties}

\subsubsection{Hardness}

The hardness or the ability of the HDPE and HDPE/DPNp composites to resist plastic deformation was determined at ambient temperature using the MicroVickers hardness indenter (Model MVI - PC, 500 gf capacity). Five samples of dimensions $15 \times 10 \times 5 \mathrm{~mm}^{3}$ were cut and polished for each of the HDPE/DPNp composites with $30,35,40$ and $45 \%$ DPNp loading. The pyramid indenter of $300 \mathrm{~g}$ on the micro-hardness tester was pressed into the smooth surface of each of the samples for 10 seconds. The hardness values were then computed as a function of the two lengths of the diagonal formed in the sample.

\subsubsection{Tensile properties}

Tensile strength was carried out on each of the produced HDPE/DPNp composites in accordance to ASTM D 638-06 on dumb-bell shaped specimens using Universal Testing machine (INSTRON 3382, 10kN capacity). The testing condition used were crosshead speed $2 \mathrm{~mm} / \mathrm{min}$ and gauge length of $50 \mathrm{~mm}$. The maximum load, $\mathrm{P}$ was recorded and the tensile strength computed from Equation 1.

$$
\sigma_{t}=\frac{P}{t \times w}
$$

Where $\sigma_{\mathrm{t}}$ is tensile strength in MPa due to tensile loading and diametrical loading respectively.

$\mathrm{P}$ is maximum load in Newton,

$t$ and $w$ are the thickness and width at the gauge length of the samples.

$\mathrm{d}_{1}$ and $\mathrm{d}_{2}$ are the internal and outer diameters respectively of the machined DPN samples while $h$ is their height. All measured in $\mathrm{mm}$.

\subsubsection{Impact energy}

The magnitude of the impact energy of a material reflects its ability to resist failure due to sudden impact. Impact test was carried out on Charpy impact testing machine with a serial number of Charpy 412-07-15269c having an inner calibration of $15 \mathrm{~J}$, with pendulum capacity of 5J according to ASTM D256. Three 
specimens for each sample were tested and the average was taken to ensure accuracy. The test was performed in accordance with the ASTM E23 standard.

\subsection{Dynamic mechanical analysis}

To understand the visco-elastic behavior of the produced doum palm nuts reinforced composites, dynamic mechanical analysis (DMA) was carried on the HDPE and each of the HDPE/DPNp composites in accordance with ASTM D4065-01. Samples with dimension $40 \times 7 \times 5 \mathrm{~mm}^{3}$ underwent 3-point bending test with a centre load of $2 \mathrm{~N}$ applied in a double cantilever configuration under varying heat conditions. The test temperature varied between 30 and $120{ }^{\circ} \mathrm{C}$ at a rate $5^{\circ} \mathrm{C} /$ min, a frequency of $10 \mathrm{~Hz}$ and amplitude of $60 \mu \mathrm{m}$. The DMA machine NETZSCH DMA 242 equipped with Proteus software gave results for storage modulus and loss modulus shown in Figure 9 to Figure 11.

\subsection{RESULTS AND DISCUSSION \\ 3.1 Density}

The density of HDPE was measured to be 0.93 $\mathrm{g} / \mathrm{cm}^{3}$ and barely changes with temperature. Although, the density of DPN was recorded at room temperature to be $1.11 \mathrm{~g} / \mathrm{cm}^{3}$, it extensively changes with temperature. Table 3 depicts that DPN lost $7.8 \%$ of its weight when heat between room temperature $\left(30^{\circ} \mathrm{C}\right)$ and $150^{\circ} \mathrm{C}$. At a heating temperature of $250^{\circ} \mathrm{C}$, DPN was found to have lost about $50 \%$ of its initial weight. The lost weight is likely to be the water and other volatile matters in the DPN. This observation is vital for understanding the dynamic mechanical behavior of the HDPE/DPNp composites. At constant volume, the density of a material depends on the mass that can be packed into the given volume under the same external conditions such as temperature and pressure [6]. Figure 4 illustrates the variations in the mean densities of X $(600 \mu \mathrm{m})$ and $\mathrm{Y}(710 \mu \mathrm{m})$ particle sizes HDPE/DPNp composites with DPNp loading. The trend of the lines in Figure 4 depicts reductions of 13.6, 19.6 and $33.3 \%$ in mean density of $X$ composites and 12.2, 18.4 and $39.8 \%$ in mean density of the $\mathrm{Y}$ composites as DPNp loading increases from 30 to 35,40 and $45 \%$ respectively. This implies that the densification of the HDPE/DPNp composites reduced with increased DPNp loading. The flowability of the HDPE in the composites might have been greatly reduced due to the addition of the DPNp. Interestingly, the HDPE/DPNp composite with the highest density (X with $30 \%$ DPNp with $0.90 \mathrm{~g} / \mathrm{cm}^{3}$ ) is lighter than the pure HDPE despite DPN being very dense.

\subsection{Static Mechanical properties}

The mechanical properties referred to as static in this study are; the tensile strength, strain, elastic modulus, hardness and impact energy. They were measured at room temperature, at zero frequency and amplitude. Figure 5 shows the first of the static properties, the tensile properties of the $\mathrm{X}$ and $\mathrm{Y}$ composites. The trend of each line depicts increase in tensile strength of the composite with increase DPNp loading. The finer particle size, X, had greater influence on tensile strength of the HDPE/DPNp composite than Y. Although, the Xcomposite experienced little change in strength as DPNp increased from $30-35 \%$, the strength of the Y-composite did not appreciate much for a wider range of reinforcement $(30-40 \%)$. Both $\mathrm{X}$ and $\mathrm{Y}$ composites showed significant rise in tensile strength from 40 to $45 \%$ DPNp loading. The maximum DPNp loading gave the maximum tensile strength, with the $\mathrm{X}$ - composite higher than the Y-composite by $17 \%$. The higher disparity in tensile strength of the two composites was at $40 \%$ DPNp loading, the X- composite was higher by $41 \%$. Interestingly, the points on the lines in Figure 4 where DPNp loading show significant effect on tensile strength represent the points where the composites had higher strength than pure HDPE (see Table 2). The relatively poor strength observed for the HDPE/DPNp composites at 30 and $35 \%$ DPNp loading could be due to poor coupling between HDPE matrix and DPNp, weak interfacial bonding [7] [8].

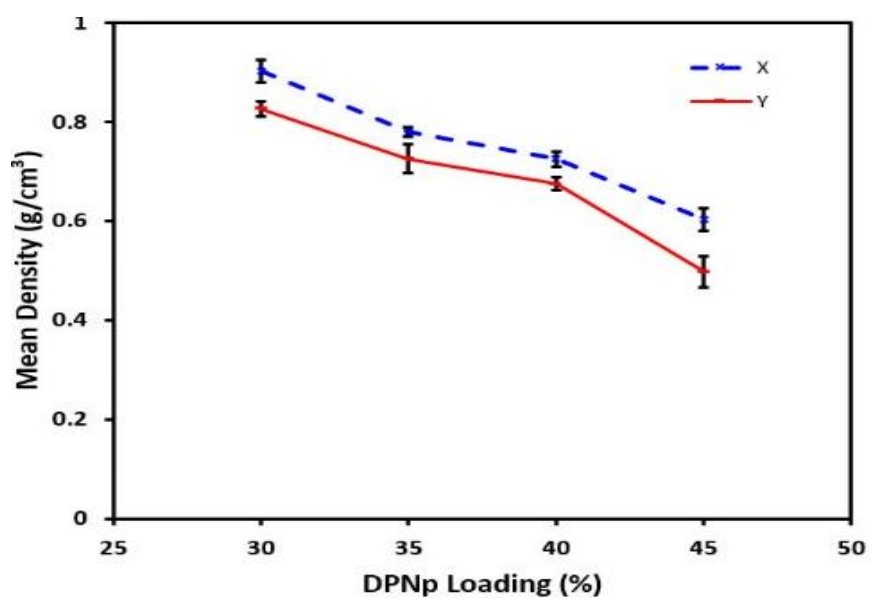

Figure 4: Mean Density of HDPE/DPNp Composite Vs DPNp Loading at $\mathrm{X}$ and $\mathrm{Y}$ Particle Sizes

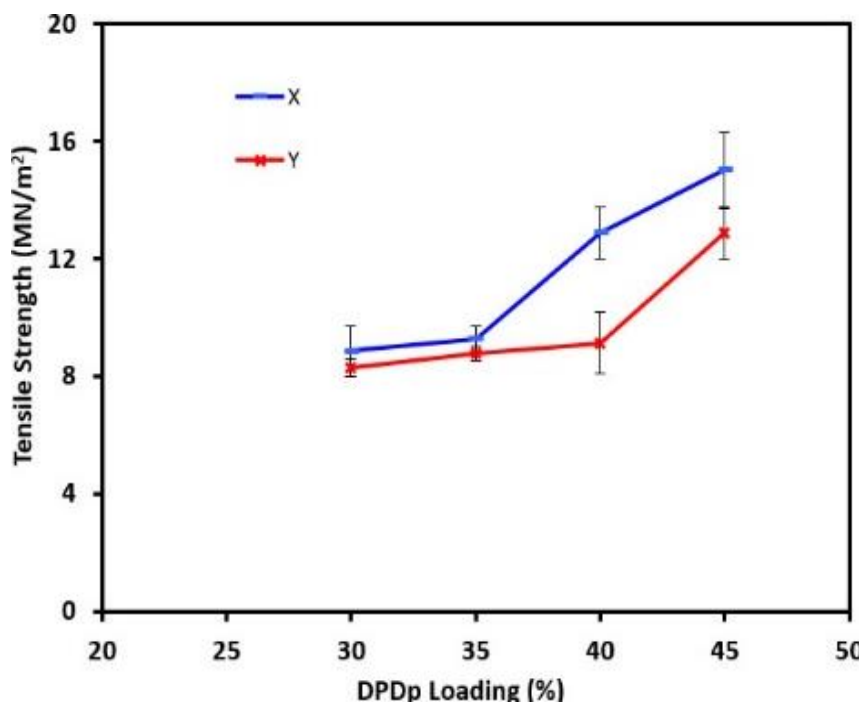

Figure 5: Tensile Strength of HDPE/DPNp Composite of $X$ and Y Particle Sizes Vs DPNp Loading 
Table 4: Mechanical Strain

\begin{tabular}{ccc}
\hline & \multicolumn{2}{c}{ Strain } \\
\hline $\begin{array}{c}\text { DPNp Loading } \\
(\%)\end{array}$ & X-Composite & Y-Composite \\
\hline 30 & 0.29 & 0.26 \\
35 & 0.27 & 0.21 \\
40 & 0.22 & 0.17 \\
45 & 0.17 & 0.14 \\
\hline
\end{tabular}

Strain value for HDPE is 0.77

Modulus of elasticity or elastic modulus, E, of a material tells it static load carrying capacity and stiffness. Figure 6 describes the influence of quantity and size of DPNp on the E of the HDPE/DPNp composites.

The trend in Figure 6 shows that DPNp loading positively influenced the modulus of elasticity of the HDPE/DPNp composites for the two particle sizes studied. The thermoformed pure HDPE had an E value of $12.37 \mathrm{MPa}$. This value is $147 \%$ less than the least value of E recorded for the DPNp reinforced HDPE. At maximum DPNp loading of $45 \%$, the stiffness of the X and Y composites were 7.5 times that of pure HDPE. This improved stiffness and load carrying capacity noted in the HDPE/DPNp composites was due to higher load sharing capacity of DPNp fibers [9] and the cellulose DPNp fibers having a higher elastic modulus than the HPDE matrix [2].

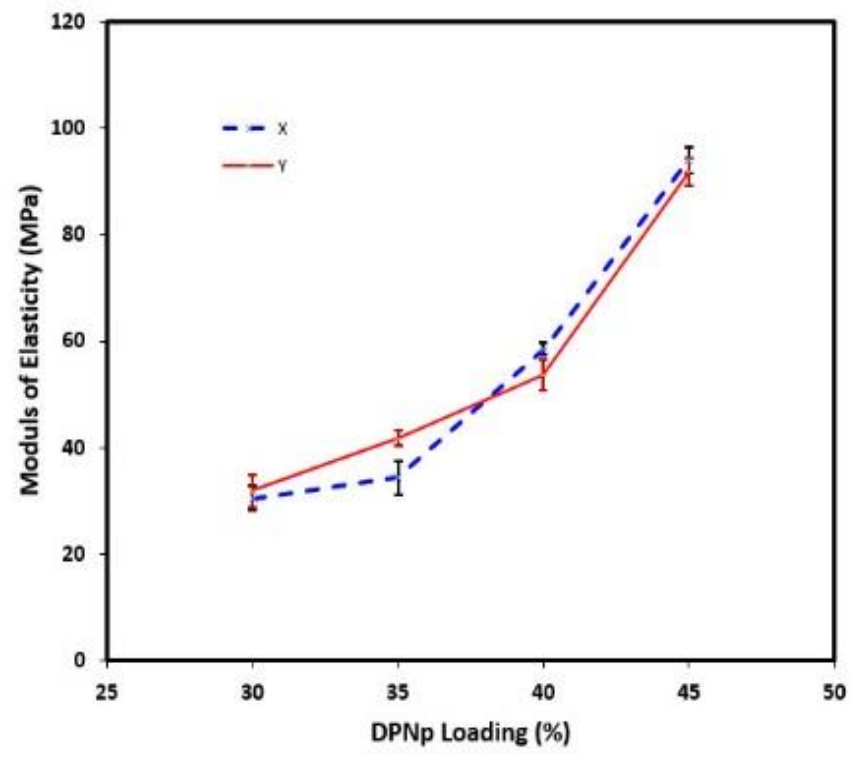

Figure 6: Modulus of Elasticity of HDPE/DPNp Composite of X and Y Particle Sizes Vs DPNp Loading

Furthermore, the larger particle sized composite (Y-composite) impacted greater stiffness in HDPE at 30 and 35\% DPNp loading but fell behind the X-composite at 40 and $45 \%$. This slight drop in stiffness of Ycomposite at higher DPNp loading could be due to the cracks formed in their structure at higher DPNp loading (see the white arrows Figure 7).

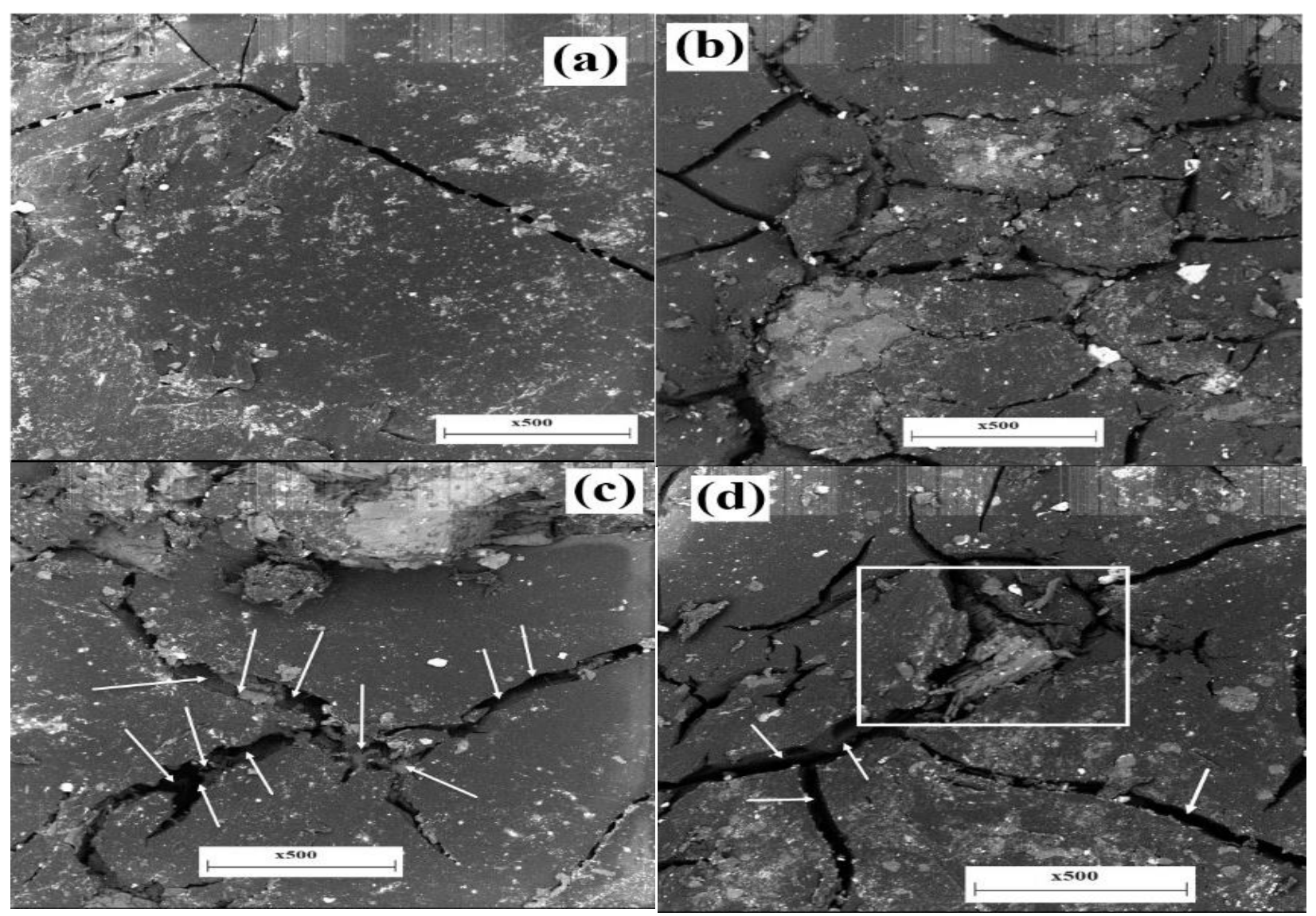

Figure 7: SEM Micrographs of HDPE/DPNp Composite Containing (a) $30 \%$ (b) $35 \%$ (c) $40 \%$ and (d) $45 \%$ Y-Particle of DPNp 
The degree of resistance of materials to indentation is known as hardness. The hardness values of pure HDPE and DPN were measured to be 18.4 and 67.6 HV respectively (see Table 2). It is observed in Figure 8 that the Vickers hardness values of the HDPE/DPNp composites increased steadily with increased DPNp loading. This shows that hardness is proportional to relative fiber volume [10][11].

The figure also depicts that the Y particle sized DPNp reinforcement had greater influence on the hardness of the composites. The addition of DPN fibers made the composites more rigid [12] thereby enhancing their resistance to indentation. The visible cracks induced in the structures of the composites as the weight and size of DPNp increased is a testimony to the improved hardness (see Figure 7 and Figure 9). The 45\% DPNp filler improved the hardness of the thermoformed HDPE by about 175 and $205 \%$ for $\mathrm{X}$ and $\mathrm{Y}$ particle sizes respectively.
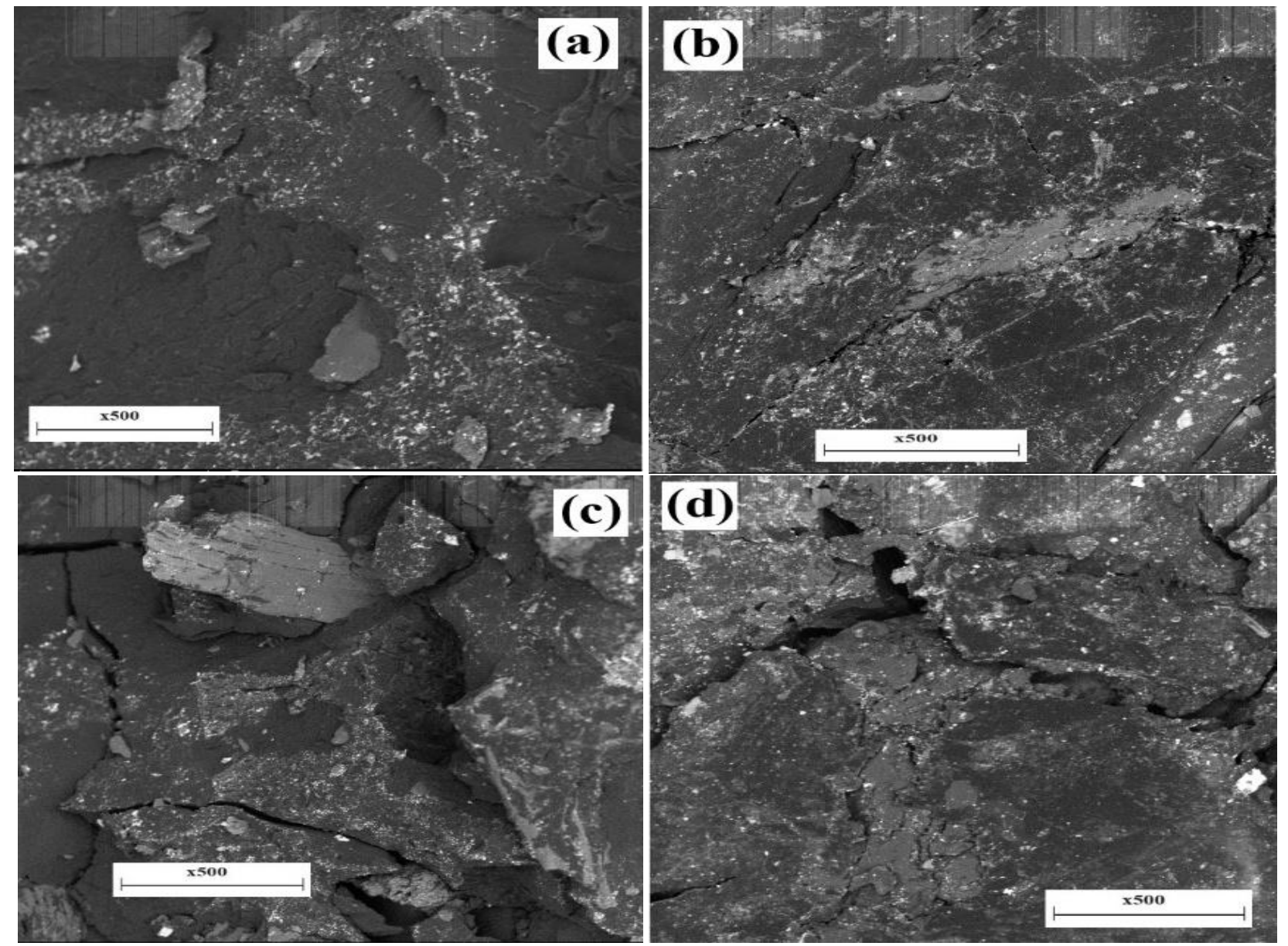

Figure 9: SEM Micrographs of HDPE/DPNp Composite Containing (a) $30 \%$ (b) $35 \%$ (c) $40 \%$ and (d) $45 \%$ X-Particle of DPNp

Figure 10 present the behavior of the HDPE/DPNp composites under impact loads. It is seen that higher energy is absorbed by the composites reinforced with the finer DPNp $(X=600 \mu \mathrm{m})$. At maximum impact energy values, the $\mathrm{X}$-composite is $57 \%$ likely to resist impact failure than the Y-composite, and

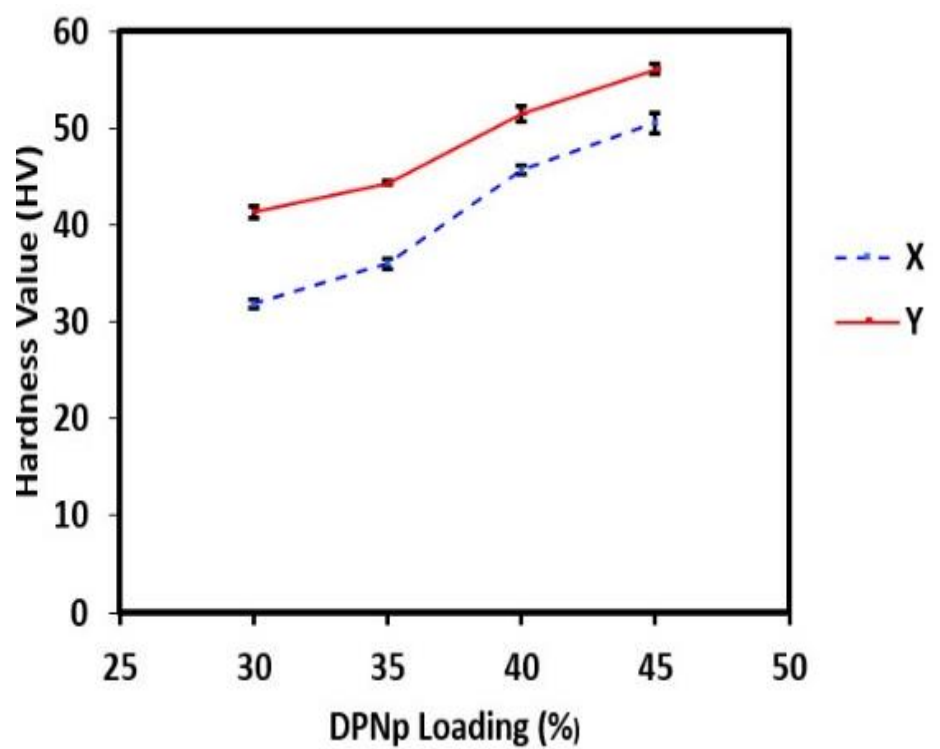

Figure 8: Hardness of HDPE/DPNp Composite of X and Y Particle Sizes Vs DPNp Loading 
tremendous improvement in impact energy over the thermoformed HPDE matrix which has a value of $0.4 \mathrm{~J}$ (see Table 2).

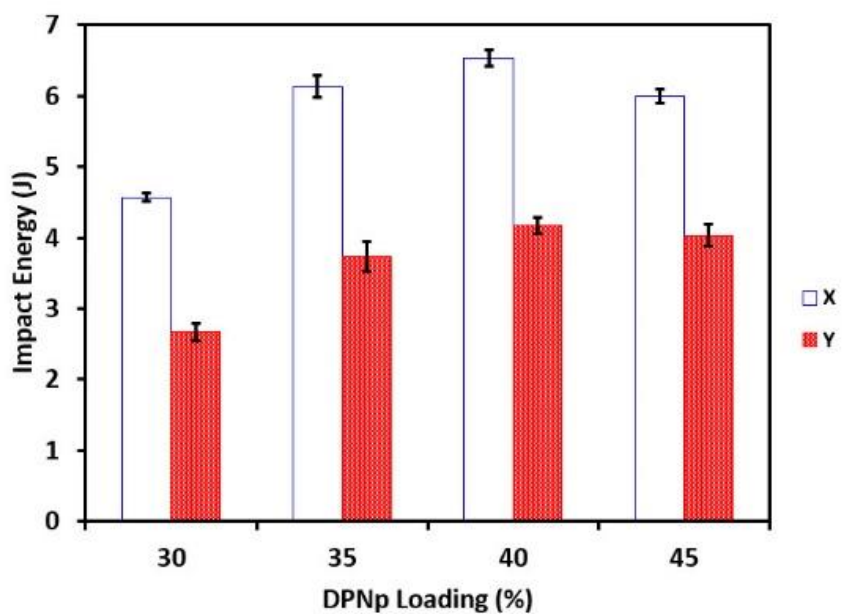

Figure 10: Impact Energy of HDPE/DPNp Composite of $X$ and Y Particle Sizes Vs DPNp Loading

\subsection{Dynamic mechanical properties}

The two dynamic mechanical properties that were looked at in this study are storage and loss modulus. The storage modulus gives an indication of the load bearing capacity of a composite material. Figure 11 and Figure 12 show the variation of storage modulus with temperature for the composites with particle size $\mathrm{X}$ and $\mathrm{Y}$ respectively. The figures also compared the behavior of the pure HDPE with the other composites.

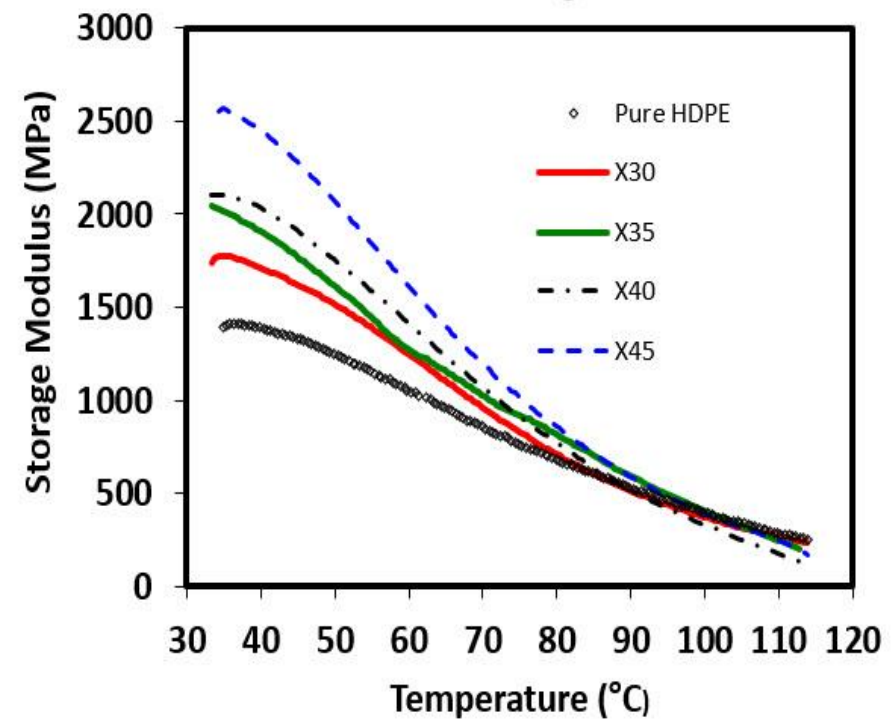

Figure 11: Storage Modulus of HDPE/DPNp Composite of XParticle Sizes

Each of the curve in the figures demonstrates the degree to which DPNp crosslinked with HDPE and provide information on the characteristics of the interfacial bonds between the HDPE/DPNp composite. The curve also categories the stiffness of each of the formed composite. It can be seen from Figure 11 that at temperature between $35-80^{\circ} \mathrm{C}$, the curves show that the DPNp loading has significant influence on the stiffness of the HDPE/DPNp composite with X particle sizes. The pure HDPE had the least storage modulus value. The storage modulus values for the $\mathrm{X}$-composite increased across the glassy and rubbery region with increase in DPNp loading. Although the value of X30 is lower than those of X35, X40 and X45, its peak storage modulus value of $1775 \mathrm{MPa}$ is $26 \%$ higher than that of pure HDPE. The peak value of $\mathrm{X} 45$ is $83 \%$ greater than that of pure HDPE. This increment in the values of storage modulus indicates improved dynamic load carrying capacity and enhanced stiffness for the X-composite due to better interfacial bonding between the DPNp/HDPE. This assertion is supported by works of [13] and [14].

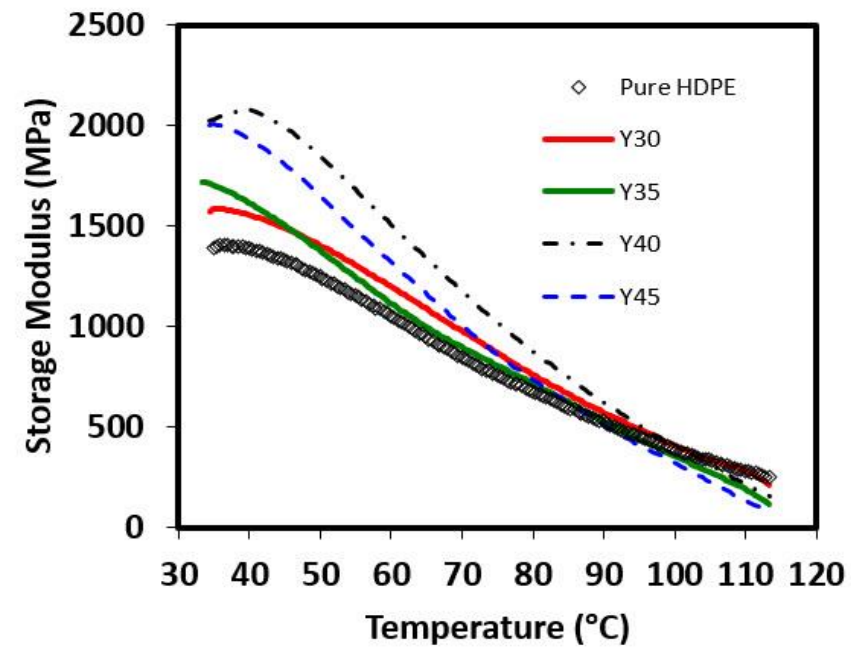

Figure 12: Storage Modulus of HDPE/DPNp Composite of YParticle Sizes

A similar trend is observed in Figure 12 for the Ycomposite except the influence of the $710 \mu \mathrm{m}$ DPNp is not as distinct as those of the $600 \mu \mathrm{m}$ in the X-composite. At elevated temperatures, water molecules within DPNp evaporate (see Table 3) making the HDPE/DPNp composite stiffer. It can be inferred that the dried cellulose within the DPNp is resistant to impact failure. Therefore, large amount of energy is required to destroy their macroscopic and microscopic structures. This claim was also affirmed by [15]. The dryness of the DPNp in the HDPE matrix contributed to the increase in storage modulus of the composite at elevated temperatures [16]. Surprisingly, Y40 exhibited a higher stiffness than Y45 despite the latter having higher amount of DPNp reinforcement. Similarly, beyond $40^{\circ} \mathrm{C}$, Y30 had higher storage modulus value than Y35. This abnormality could be due to the cracks in the structures of the Y-composite (see Figure 7). This crack formation and propagation is an indication of weak fiber-matrix bond in the composite [17]. Unlike the X-composite, more cracks were formed in the Y-composite than in the X-composite (see Figure 7 and Figure 9). 
The larger DPN particle sizes in the Y-composite might have made it more difficult to thermoform than the $\mathrm{X}$-composite. The structure of Y45 contains more cracks than Y40, it's structure also indicated traced of incompletely melted HDPE. These defects show that Y40 contained better interfacial bonds than $\mathrm{Y} 45$ and the former is less susceptible to crack propagation under dynamic loads. These could be responsible for Y45 exhibiting lower storage modulus Y40.

Loss modulus defines the heat energy lost per cycle of deformation [18]. It also provides information on the viscous nature of materials. Figure 13 and Figure 14 show the variation of loss modulus with temperature for the composites with particle size $\mathrm{X}$ and $\mathrm{Y}$ respectively. The figures also show viscous behaviour of pure HDPE. Pure HDPE reported the highest loss modulus for the range of temperature studied. The values of the loss modulus decrease as the DPNp loading increases from $30 \%$ to $45 \%$. This reduction in loss modulus is due to restriction of the relaxation process within the composites and reduction in amplitude of vibration due to reduced viscosity. This assertion is supported by the works of [19].

The figures also show that the composites reinforced with the finer particle sizes (X-composite) loss less heat energy during the cyclic deformation. For instance, X30 has lower loss modulus than Y30 because the finer particle sizes in $\mathrm{X} 30$ restricted its relaxation more than the larger particles in Y30 did. This restriction makes Y30 more viscous and prone to loss more energy than $\mathrm{X} 30$. Y35, Y40 and Y45 show close viscous behaviour (see Figure 14) with overlapping values of loss modulus. Increase in DPNp loading does not significantly affect the viscous behaviour of the Y-composites beyond $35 \%$. Interestingly, the SEM structure of Y40 and Y45 contain wider cracks (see the white arrows in Figure 7) which implies that they are less viscous.

\subsection{CONCLUSION}

The following conclusions can be drawn:

i. Doum palm nut particles were successfully used to reinforced HDPE.

ii. The HDPE composite with the lesser particle size exhibits greater density compared with the greater particle size reinforced HDPE composite

iii. The density of each of the HDPE/DPNp composite produced is lower than that of pure HDPE. This makes the composite suitable in light-weight application

iv. The DPNp has proven to be an excellent reinforcement for HDPE. It improved the tensile strength of HDPE by over 50\%. The load carrying capacity and stiffness of HDPE was increased 8fold. DPNp has further enhanced the hardness of HDPE by about $200 \%$ and its resistance to impact failure by over $1500 \%$.

v. HDPE reinforced with DPNp of lesser particle size (X-composite) exhibited better static and dynamic mechanical properties

vi. Reinforcing HDPE with DPNp also impacted superior dynamic load carrying capacity on the composite over the pure HDPE.

vii. The lightweight of the produced HDPE/DPNp composite coupled with its great stiffness, superior hardness, high resistance to impact failure and ability to maintain high load carrying capacity under dynamic conditions could make the composite suitable for casing sensitive electronic equipment.

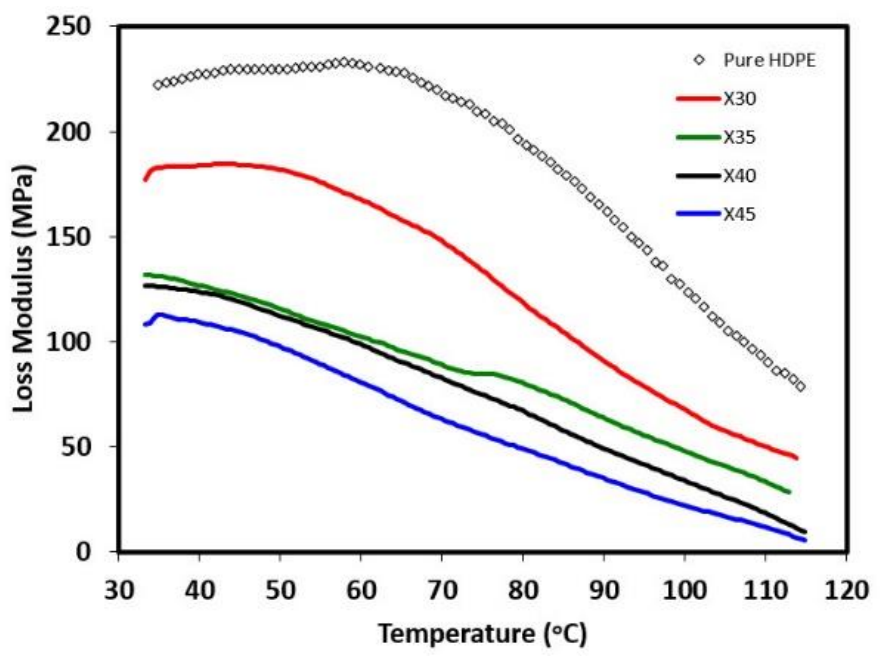

Figure 13: Loss Modulus of HDPE/DPNp Composite of XParticle Sizes

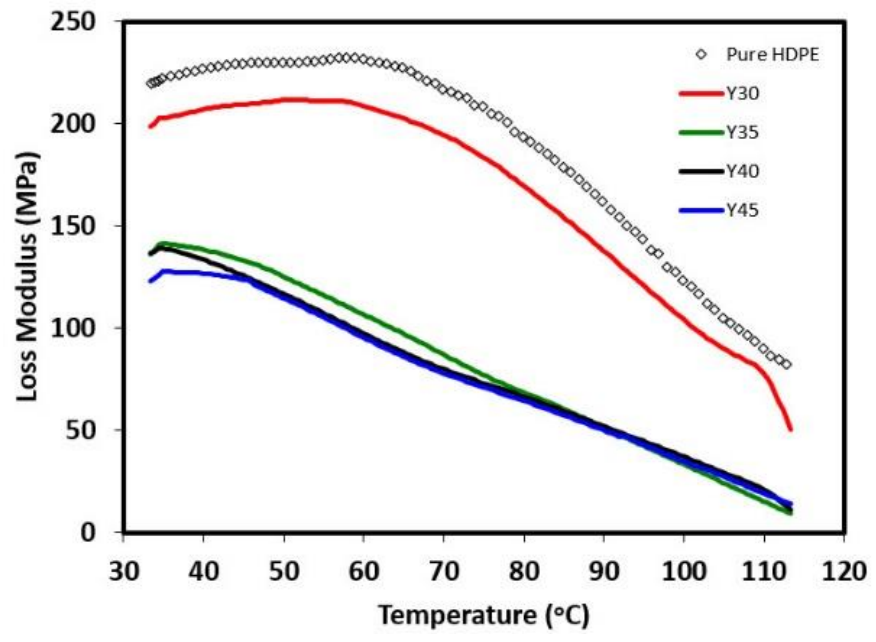

Figure 14: Loss Modulus of HDPE/DPNp Composite of YParticle Sizes

\section{REFERENCES}

[1] Orwa, C., Mutua, A., Kindt, R., Jamnadass, R. and Anthony, S. "Agroforestree Database:a tree reference and selection guide version 4.0," (2009).

[2] Jústiz-Smith, N. G., Virgo, G. J. and Buchanan, V. E. "Potential of Jamaican banana, coconut coir and bagasse fibres as composite materials." Materials characterization, 59(9), (2008), 1273-1278. 
[3] Arrakhiz, F.Z., El Achaby, M., Malha, M., Bensalah, M.O., Fassi-Fehri, O., Bouhfid, R., Benmoussa, K. and Qaiss, A. "Mechanical and thermal properties of natural fibers reinforced polymer composites: Doum/low density polyethylene." Materials \& Design, 43, (2013), 200-205.

[4] Shinoj, S., Visvanathan, R., Panigrahi, S. and Kochubabu, M. "Oil palm fiber (OPF) and its composites: A review." Industrial Crops and products 33(1), (2011), 7-22.

[5] Li, Y., Du, L., Kai, C., Huang, R. and Wu, Q. "Bamboo and high density polyethylene composite with heat-treated bamboo fiber: Thermal decomposition properties," BioResources, 8(1), (2013), 900-912.

[6] Alabi, A.A., Tahir, S.M., Zahari, N.I., Hanim, M.A. and Anuar, M.S. "A modified diametrical compression test technique (MDCTT) for mode II fracture toughness of iron powder compact." Powder Technology, 319, (2017), 356364.

[7] Adhikary, K.B., Pang, S. and Staiger, M.P. "Dimensional stability and mechanical behaviour of wood-plastic composites based on recycled and virgin high-density polyethylene (HDPE)." Composites Part B: Engineering, 39(5), (2008), 807-815.

[8] Khanam, P.N. and AlMaadeed, M.A. "Improvement of ternary recycled polymer blend reinforced with date palm fibre." Materials \& Design, 60, (2014), 532-539.

[9] Inbakumar, J.P. and Ramesh, S. "Mechanical, wear and thermal behaviour of hemp fibre/egg shell particle reinforced epoxy resin bio composite." Transactions of the Canadian Society for Mechanical Engineering, 42(3), (2018), 280285.

[10] El-Shekeil, Y.A., Sapuan, S.M., Abdan, K. and Zainudin, E.S. "Influence of fiber content on the mechanical and thermal properties of Kenaf fiber reinforced thermoplastic polyurethane composites." Materials \& Design, 40, (2012), 299-303.
[11] Pokhriyal, M., Prasad, L. and Raturi, H.P. "An experimental investigation on mechanical and tribological properties of Himalayan nettle fiber composite." Journal of natural fibers, 15(5), (2018), 752-761.

[12] Haque, M.M., Islam, M.S. and Islam, M.N. "Preparation and characterization of polypropylene composites reinforced with chemically treated coir." Journal of Polymer Research 19(5), (2012), 1-8.

[13] Doddamani, M. "Dynamic mechanical analysis of 3D printed eco-friendly lightweight composite." Composites Communications, 19, (2020), 177-181.

[14] Eldesouky, H. M. G., and Brachman, R. W. I. "Viscoplastic modelling of HDPE geomembrane local stresses and strains." Geotextiles and Geomembranes 48(1), (2020), 41-51.

[15] Klemm, D., Philpp, B., Heinze, T., Heinze, U. and Wagenknecht, W. "Volume 1: Fundamentals and analytical methods.," in Comprehensive cellulose chemistry., Wiley-VCH Verlag GmbH. (1998).

[16] Pothan, L.A., Oommen, Z. and Thomas, S. "Dynamic mechanical analysis of banana fiber reinforced polyester composites." Composites Science and technology 63(2), (2003), 283-293.

[17] M. M. Shokrieh and Mohammadi, A. R. G. "The importance of measuring residual stresses in composite materials," in Residual Stresses in Composite Materials, Second., Woodhead Publishing Series in Composites Science and Engineering, (2021), 3-17.

[18] Oboh, J.O., Okafor, J.O., Kovo, A.S. and Abdulrahman, A.S. "Dynamic mechanical properties of crosslinked natural rubber composites reinforced with cellulosic nanoparticles." Nigerian Journal of Technology, 37(3), (2018), 668-673.

[19] Asim, M., Jawaid, M., Paridah, M.T., Saba, N., Nasir, M. and Shahroze, R.M. "Dynamic and thermo-mechanical properties of hybridized kenaf/PALF reinforced phenolic composites." Polymer Composites, 40(10), (2019), 3814-3822. 